\title{
Creating a Green Chemistry Lab: Towards Sustainable Resource Management and Responsible Purchasing
}

\author{
Junkal Gutierrez ${ }^{1,2}{ }^{\oplus}$, Arrate Santaolalla ${ }^{1}$, Agnieszka Tercjak ${ }^{2}{ }^{\circledR}$, Naiara Rojo ${ }^{1}$, \\ Dolores Encinas ${ }^{1}$, Zuriñe Gomez-de-Balugera ${ }^{1}$ and Gorka Gallastegui ${ }^{1, *(D)}$ \\ 1 Department of Chemical and Environmental Engineering, Faculty of Engineering Vitoria-Gasteiz, \\ University of the Basque Country (UPV/EHU), C/ Nieves Cano 12, 01006 Vitoria-Gasteiz, Spain; \\ juncal.gutierrez@ehu.eus (J.G.); arrate.santaolalla@ehu.eus (A.S.); naiara.rojo@ehu.eus (N.R.); \\ loli.encinas@ehu.eus (D.E.); z.gomezdebalugera@ehu.eus (Z.G.-d.-B.) \\ 2 Group 'Materials+Technologies' (GMT), Department of Chemical and Environmental Engineering, \\ Faculty of Engineering Gipuzkoa, University of the Basque Country (UPV/EHU), Plaza Europa 1, \\ 20018 Donostia-San Sebastian, Spain; agnieszka.tercjaks@ehu.eus \\ * Correspondence: gorkajavier.gallastegui@ehu.eus
}

Received: 23 September 2020; Accepted: 26 October 2020; Published: 27 October 2020

\begin{abstract}
The main goal of this project was to improve the efficiency and sustainability of the chemistry teaching laboratories of the Faculty of Engineering Vitoria-Gasteiz (University of the Basque Country (UPV/EHU)). With this aim, three different actions were developed. The first two actions aspired to achieve and maintain order and maximize efficiency within the facilities. With this in mind, the first phase involved carrying out an inventory, classifying, and rearranging all the chemical products in the warehouse using a computer storage system. Secondly, $5 S$ lean methodology was implemented in the laboratories. The final phase included the development of a protocol for a joint purchasing strategy of chemical reagents that fostered a more responsible and sustainable acquisition and management of the substances used in various departments of the UPV/EHU. This protocol plays a key role in the transition towards the Circular Economy and its importance lies in the fact that it could be extended to other departments and faculties with similar needs. This project was developed during last two academic years (2017/2019) in the frame of the Campus Bizia Lab Programme, an initiative created to address sustainability challenges within the University.
\end{abstract}

Keywords: chemistry lab; circular economy; healthy environments; 5S methodology

\section{Introduction}

In September 2015, the United Nations established "Agenda 2030 for Sustainable Development" with 17 "Sustainable Development Goals" (SDGs) and 169 targets for the year 2030. This agenda received the adhesion of 193 countries, which committed to mobilize all the necessary means to implement it. Albeit global in nature, matters related to sustainable development are best handled at the local level, and, thus, the involvement of macropolitical institutions must filter down to those levels of authority closest to the citizen. One example of this is the "EHUagenda 2030, For sustainable development", a route map seeking to bring the work of the University of the Basque Country (UPV/EHU) into line with the planet's biggest challenges, moving towards a verifiable, pragmatic contribution. Among other objectives, EHUAgenda 2030 goes in pursuit of a consistent integration of the specific local efforts of students, teaching staff, researchers, and administration and services personnel in connection with the SDGs. 
Sustainable management and development seeks to protect human health and the health of the planet. This strategy intends to consolidate goals, such as optimizing the consumption of materials and resources or responsible management of the waste generated, paving the way for a circular economy model [1].

Nowadays, the concept of "circular economy" is trending in all fields and at all levels from children to adults (citizenship, companies, organizations and universities, among others). As reported by Scopus database (2020) [2], the exponential growth of the number of publications related to this topic from 190 in 2015 to 1300 in a short period of three years gives an idea of its magnitude. Regarding its applicability, Figure 1 clearly shows the multidisciplinary level of this topic.

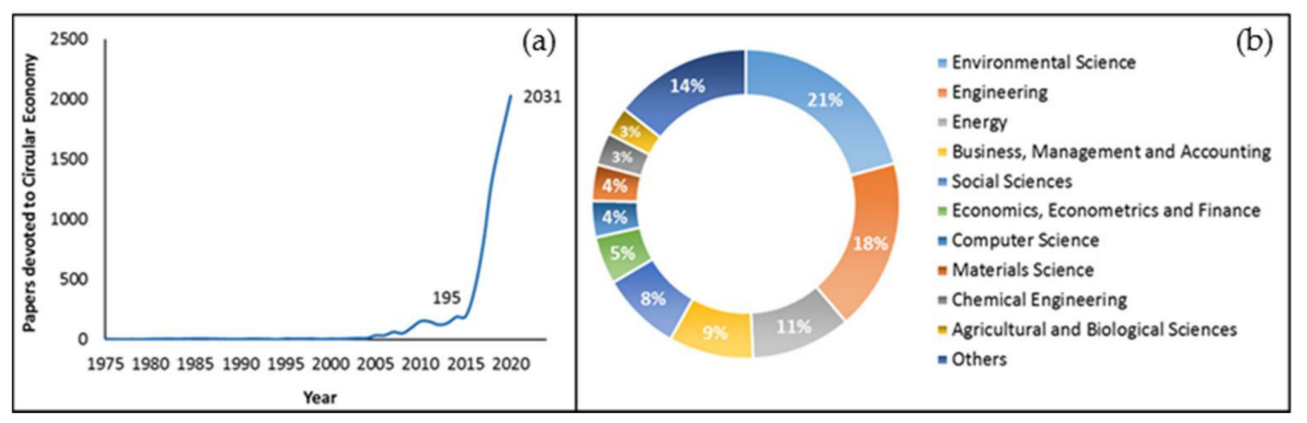

Figure 1. Published scientific articles that contain the term circular economy: (a) Analyzed per year; (b) by subject area.

Therefore, the absence of a standard definition for this concept is easy to understand [3]. However, an accurate definition was proposed by Kalmykova and coworkers (2018) [4]: "A circular economy is an alternative to a traditional linear economy (make, use, dispose) in which we keep resources in use for as long as possible, extract the maximum value from them whilst in use, then recover and regenerate products and materials at the end of each service life". In conclusion, the circular economy constitutes a paradigm that facilitates the transition of organizations to a more sustainable model [1].

Taking into account the close relationship between circular economy and sustainable management and development, the university sector has begun in recent years to address both terms and to engage with the ambitious challenge of introducing a shift in the order of priorities of citizenship. Some of these initiatives include the truly pioneering and innovative circular economy-oriented research and teaching programs developed by the University of Bradford, Delft University of Technology, Arizona State University, and University College London, amongst others. All of them are partners of the Ellen MacArthur Foundation, which works with higher education institutions worldwide to develop, share, and scale circular economy learning [5].

Within this framework, the UPV/EHU has also assumed the challenge to contribute constructively and critically to the promotion of the circular economy. To that end, UPV/EHU created the so-called "Campus Bizia Lab Programme" (CBLP) in 2016 to tackle sustainability challenges within the University [6]. This initiative is a follow-up to the "University Educators for Sustainable Development" project included in the European Union Lifelong Learning Programme 2007/2013 for education and training. CBLP was created under the umbrella of the Sustainability Directorate and Educational Advisory Service with the objective of promoting a close working relationship between the different members of the University: Teaching and Research Staff, Administration and Services Staff, and students, with the latter playing a pivotal role as they are the primary users of campus services [7].

The work described herein was carried out during two academic years (2017/2019) in the framework of CBLP of the UPV/EHU. The project involved three different actions, each of them reflected in an End-of-Degree project. 


\section{Framework}

The first two actions of the project aspired to achieve and maintain order and maximize efficiency by means of $5 S$ methodology in the teaching laboratories and warehouse of the Chemical and Environmental Engineering Department of the Faculty of Engineering Vitoria-Gasteiz (UPV/EHU). As reflected in its Strategic Plan 2015/2018 [8], this institution aspires to train graduates in the principles of sustainable development, as well as in values, such as professional ethics, cooperation, commitment, and integrity, fundamental in engineers that will be catalysts of change in society. The Faculty is formed by approximately 110 teachers, 23 administration and services staff, and 850 students. Currently, it provides four-year degree programs for five different bachelor's degrees (Mechanical Engineering, Industrial Electronic Engineering and Automatic, Computer Management and Information Systems Engineering, Industrial Chemical Engineering, and Automotive Engineering) through the participation of 15 Departments among which the Chemical and Environmental Engineering Department is included. Members of the latter Department formed the team of this project.

The third activity consisted in the development a protocol for a joint purchasing strategy of chemical reagents. In order to attain this target, four partners joined this pilot project: Three Departments at the Álava Campus and one at the Bizkaia Campus of the UPV/EHU, which were together in charge of 12 different experimental subjects with an attendance of more than 700 students per year (Table 1).

Table 1. List of project partners and experimental subjects involved.

\begin{tabular}{|c|c|c|c|c|}
\hline Campus & Centre & Bachelor/Master Degree & Department & Subject \\
\hline \multirow{12}{*}{ 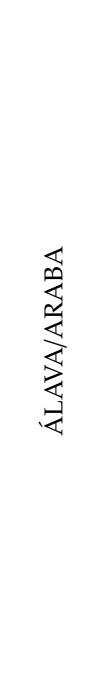 } & \multirow{2}{*}{$\begin{array}{l}\text { Faculty of Engineering } \\
\text { Vitoria-Gasteiz }\end{array}$} & \multirow{2}{*}{$\begin{array}{l}\text { Industrial Chemical } \\
\text { Engineering }\end{array}$} & \multirow{2}{*}{$\begin{array}{l}\text { Chemical and } \\
\text { Environmental Engineering }\end{array}$} & $\begin{array}{l}\text { Chemical Principles of } \\
\text { Engineering }\end{array}$ \\
\hline & & & & $\begin{array}{c}\text { Experimentation in } \\
\text { Chemical Engineering }\end{array}$ \\
\hline & \multirow{10}{*}{$\begin{array}{l}\text { Faculty of Pharmacy } \\
\text { Vitoria-Gasteiz }\end{array}$} & \multirow{3}{*}{ Environmental Sciences } & \multirow{2}{*}{ Analytical Chemistry } & Analysis of Pollutants \\
\hline & & & & Contamination Case Studies \\
\hline & & & Inorganic Chemistry & Chemistry I \\
\hline & & \multirow{2}{*}{$\begin{array}{l}\text { Foods Science and } \\
\text { Technology }\end{array}$} & Analytical Chemistry & Chemical Analysis \\
\hline & & & Inorganic Chemistry & Nanotechnology \\
\hline & & Oenology & Analytical Chemistry & Oenology \\
\hline & & \multirow[b]{2}{*}{ Pharmacy } & Analytical Chemistry & Analytical Chemistry \\
\hline & & & Inorganic Chemistry & $\begin{array}{l}\text { General and Inorganic } \\
\text { Chemistry }\end{array}$ \\
\hline & & \multirow[b]{2}{*}{ Forensic analysis } & \multirow[b]{2}{*}{ Analytical Chemistry } & Toxicology \\
\hline & & & & $\begin{array}{l}\text { Forensic Analytical } \\
\text { Chemistry }\end{array}$ \\
\hline \multirow{2}{*}{ 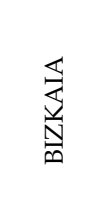 } & \multirow{2}{*}{$\begin{array}{l}\text { Faculty of Engineering } \\
\text { in Bilbao }\end{array}$} & $\begin{array}{l}\text { Advanced Materials } \\
\text { Engineering }\end{array}$ & $\begin{array}{l}\text { Mining and Metallurgical } \\
\text { Engineering and Materials } \\
\text { Science }\end{array}$ & $\begin{array}{l}\text { Structure and Properties of } \\
\text { Polymeric Materials }\end{array}$ \\
\hline & & $\begin{array}{l}\text { Industrial Technology } \\
\text { Engineering }\end{array}$ & $\begin{array}{l}\text { Mining and Metallurgical } \\
\text { Engineering and Materials } \\
\text { Science }\end{array}$ & $\begin{array}{c}\text { Structural Materials: } \\
\text { in-service behaviour and } \\
\text { fracture mechanics }\end{array}$ \\
\hline
\end{tabular}

\section{Objectives}

The first two actions of this project were focused on the 5S methodology, the main goal of which is to eliminate non-value adding processes by standardizing working methods and creating a well-organized working environment [9]. In our particular case, such an action was set in order to prevent time wasting, to reduce walking distances and, most importantly, to increase safety and prevention.

Besides, the third action addressed a broader and more ambitious objective as achieving the transition to a circular economy developing a protocol for a joint purchasing strategy of chemical reagents for the entire University (UPV/EHU) that enables more responsible and sustainable acquisition and management of these substances. 


\section{Sustainable Efforts Make a Difference}

The chemical warehouses and laboratories of both Universities and Technology Centers entail a series of specific problems that provoke the waste of resources and the excessive generation of hazardous wastes. As reported by Dolgin (2018) [10], there are six main reasons that contribute to the accumulation of chemical reagents and other disused materials (Figure 2). The fact that, for whatever reason, a large amount of resources are wasted, whether in the form of laboratory equipment or chemical substances, causes an unnecessary expense for the institutions.

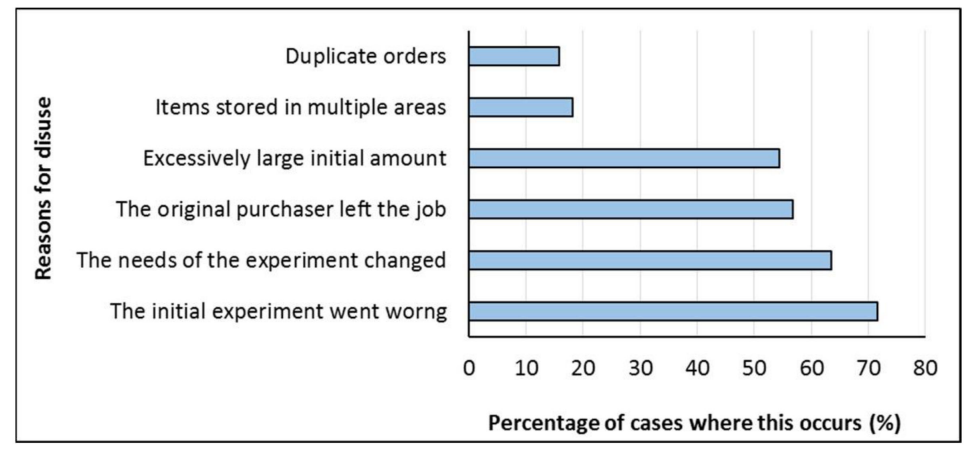

Figure 2. Most commonly repeated reasons for which equipment and other lab issues fall into disuse in warehouses of educational centers and research facilities. Adapted from [10].

Besides, given the absence of a responsible manager with full authority to decide what to do with these kinds of materials there is a tendency to act according to the maxim that anything that is not used should be kept for a hypothetical further application. Obviously, this results in the accumulation of different substances being located in various storage areas. Consequently, what at first sight seems to be a highly beneficial practice, becomes a waste of useful warehouse space and finally an additional economic expense caused by the necessary removal of outdated equipment or expired compounds.

\subsection{S Methodology}

All these inconveniences were detected in the warehouse and laboratories of the Chemical and Environmental Engineering Department at the Faculty of Engineering Vitoria-Gasteiz. Accordingly, the first action of the project (2017/2018 academic year) consisted of carrying out an inventory, classifying, and rearranging the reagents and chemical products in the warehouse, improving at the same time the methodology employed to store new reagents.

Given the fact that the chemical reagent warehouse should have a structure similar to any industrial warehouse, a model based on the management technique called "5S", common in this type of environment, was proposed. The $5 \mathrm{~S}$ lean tool is known to improve system performance and is considered to play a significant role in establishing a Total Quality Management (TQM) environment [11,12]. With implementation of the $5 \mathrm{~S}$ management method (hereinafter abbreviated as $5 S$ ) in university facilities, such installations become industrial ones and commit themselves to adopt the conditions of security and organization usually found in industry.

5S, which stands for the five Japanese words Seiri, Seiton, Seiso, Seiketsu, and Shitsuke, has been traditionally used in the automotive and other industries and comprises a set of low-cost and technologically undemanding practices that aim to generate productivity improvements by creating and sustaining clean and well-organized workplaces [13].

- $\quad$ Step 1: Seiri-Sort

Seiri involves sorting through the contents of the workplace and removing unnecessary items. This action is devoted to identifying and eliminating all unnecessary items from the workplace. In accordance with the guidelines contained in the 5S Manual [14], necessary items include those 
substances that will definitely be used in the future. By the same token, unnecessary items are those compounds that are not intended to be used in the future or within a specific time period. Experience shows that the main challenge is establishing the time limit to distinguish between what is necessary and unnecessary.

\section{- $\quad$ Step 2: Seiton-Set in Order}

Seiton establishes the need to keep necessary items in designated locations for easy and timely retrieval. In this case, the work team meet to design the criteria for the organization. The criterion of frequency of use is taken as a basis, placing the more highly demanded compounds within arm's reach, and those less required compounds in cabinets or more distant locations.

- Step 3: Seiso-Shine

Seiso is focused on keeping the facilities neat and clean. It should be pointed out that cleaning is not a goal in itself, but the final task accompanying any other activity carried out in the facilities.

- $\quad$ Step 4: Seiketsu—Standardise

Seiketsu enables and ensures compliance with the new standards established in the first three steps for a well-articulated and consistently organized working procedure. Procedures and schedules are written and visual management tools, such as color coding, signals (showing direction or position), labels, posters, and photos, were strategically positioned.

- Step 5: Shitsuke-Sustain

Shitsuke consolidates and brings together all the previous steps. It involves training and discipline to ensure that everyone follows the $5 \mathrm{~S}$ standards. In this case, the goal is to sustain the previous four steps and intensify efforts to seek an improvement in each of them.

In the particular case of the aforementioned chemical reagents warehouse, the analysis of the initial situation (Figure 3) revealed several problems, such as accumulation of reagents, excessive weight on shelves and improper storage of reagents that can cause unexpected reactions, prohibited storage, and corrosion and dirtiness, and so forth.
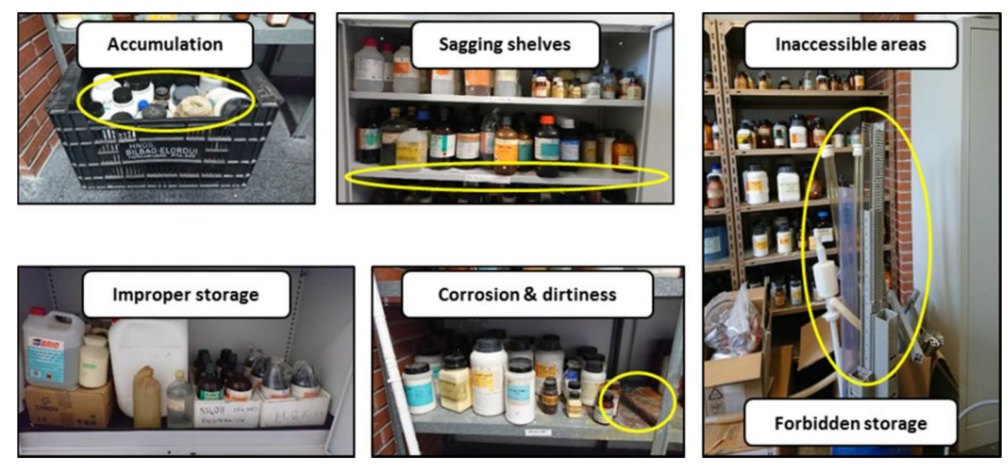

Figure 3. Initial situation of the warehouse of the Chemical and Environmental Engineering Department at the Faculty of Engineering Vitoria-Gasteiz.

\subsection{Internal Evaluation: Forecasting the Acceptance Rate of the Joint Purchasing Protocol}

A survey was conducted on University members assigned to Chemistry teaching labs relating to their different degrees of willingness in the application of the sustainability initiatives described in this project, as well as the numerous uncoordinated actions carried out to deal with the accumulation of chemical reagents in the warehouses. 


\section{Results and Discussion}

Figures 4 and 5 illustrate the overall plan executed within the warehouse. As mentioned in the previous section, the first step of $5 S$ (Seiri, 1S) focused on the removal of unnecessary items. Accordingly, the warehouse was completely emptied and all the chemical reagents were properly checked and classified. The size of this challenge should not be underestimated, taking into account that the shelves were stocked with more than 1200 compounds.
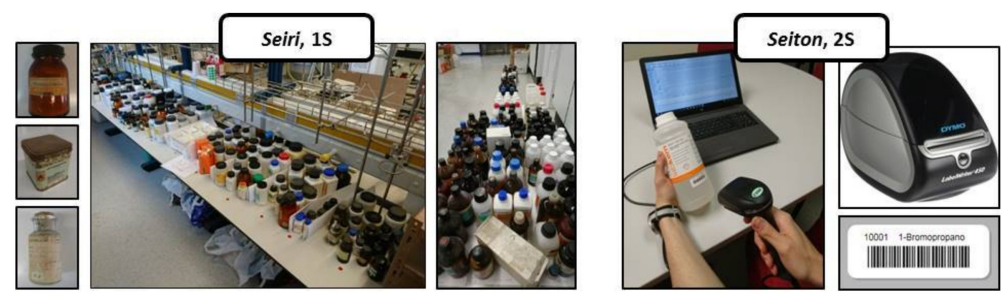

Figure 4. Sort (1S) and set in order (2S) steps of 5S methodology application.

During the inventory process, $25 \%$ of the chemical reagents were discarded given their poor conditions. The increase in the volume of chemical residues generated during this phase was reflected in the corresponding invoice sent by the waste management company to the Faculty of Engineering of Vitoria-Gasteiz at the end of 2018.
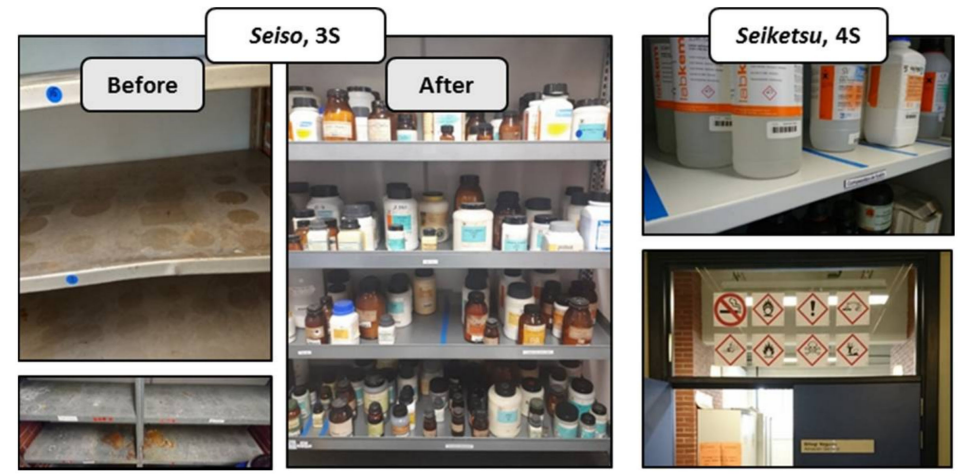

Figure 5. Shine (3S) and standardize (4S) steps of 5S methodology application.

The amount increased 1.65-fold times in comparison with the average of the previous four years (Figure 6). The peak of residue production that occurred in 2016 is attributed to the closure of the Material Science Department. This made it perfectly clear that a storage methodology that includes periodic revisions should be established to avoid the repetition of previous episodes of lack of care.

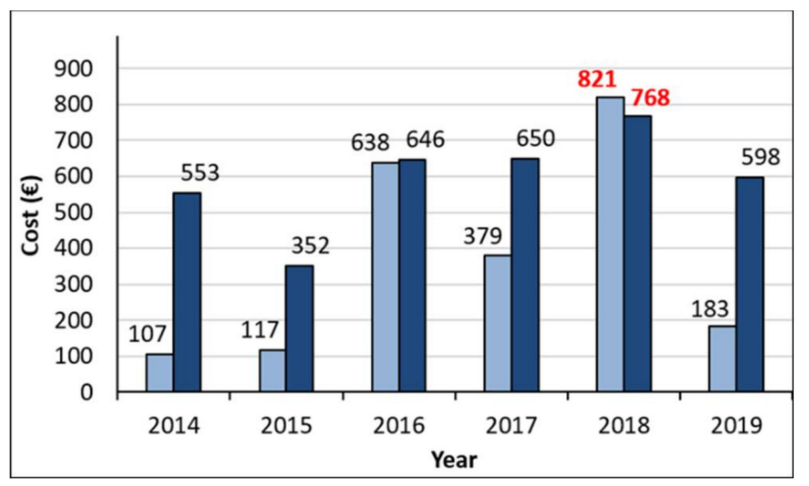

Figure 6. Costs associated with the management (light blue) and transport (including the necessary acquisition of consumables, such as bags, drums, or labels) (dark blue) of laboratory residues generated by the Faculty of Engineering of Vitoria-Gasteiz (UPV/EHU). 
In this vein, it was also observed that within the category of "reagents in good conditions", there was a surplus of some, which were not expected to be used in a near future, either because they were highly specific substances or because they belonged to former research lines. These reagents were at risk of becoming hazardous waste sooner rather than later, in which case they should be classified and treated as laboratory reagent waste $(1850 € / \mathrm{T})$ by means of the Sustainability Directorate and Educational Advisory Service, an agency under the Vice-Rectorate for Innovation, Social Outreach and Cultural Activities of the UPV/EHU [15]. The associated cost of this management would be added to the purchase cost becoming a significant waste of money for the UPV/EHU.

Location and identification of the chemical reagents was determined during the Seiton stage (2S). Therefore, it was necessary to follow a chemical reagents segregation chart for a proper location of non-compatible chemicals in the warehouse [16]. In addition, frequency of use, ergonomics, accessibility, and shape and/or weight issues were also taken into account.

These first two steps enabled the creation of a database in which the reagent was registered with 16 specifications (e.g., chemical formula, CAS, manufacturer, purity, available quantity, or type of container), along with its location in the warehouse. With this aim, the Quartzy program was selected as an online database. To gain better control, it was decided to go one step further by computerizing the inventory of the warehouse using the Velneo application. The computerized system consisted of a device that contained the database, a barcode scanner and printer that enabled the identification of each reagent directly from the database. Thus, all reagents were labelled with a barcode. This new barcode inventory system enabled the user to determine with just one click all information about the chemical reagent and its location in the warehouse, greatly reducing search times. Moreover, this system was also able to record the information about the entry and exit of reagents. Finally, it is important to mention that Quartzy and Velneo are compatible databases.

As shown in Figure 5, in the third stage, (Seiso, 3S), both the warehouse facilities and all containers of the reagents were cleaned and the furniture in poor condition was replaced. Following that, magnetic signs and the corresponding safety pictograms (Seiketsu, 4S) were placed (Figure 5). Additionally, a reagent containment bund was also installed to facilitate reagent transfers. To complete this step, a user manual was also prepared so that any person could quickly and easily learn the operation of the warehouse and use it without problem. Finally, in order to maintain the high standards established during the process, a timetable of revisions was established. A laboratory technician was responsible for periodic reviews.

Completing this work allowed us to know in detail the quantity of reagents that were housed inside the warehouse, as well as to assess their status and discard those that were not in optimal conditions. Thus, it was concluded that the problem of disorder in the warehouse was solved thus enabling the systematic search for any substance. The final result included the implementation of an efficient computerized chemical reagent storage system that allowed a better use of the resources available to the Chemical and Environmental Engineering Department and moreover, significantly facilitated the teaching work of the Teaching and Research Staff and Administration and Services Staff associated with it.

However, it should be emphasized that $5 \mathrm{~S}$ is more than simply a cleaning-up or housekeeping activity: It is the foundation block upon which a company can build its lean initiative [11].

In addition, it is a visual management tool and a structured methodology for creating best practices in a clean, organized, and efficient working environment. As such, it can assist with the elimination of frustration, stress, space limitation, and inventory management. In short, $5 \mathrm{~S}$ is a good way to manage university warehouses and laboratories, and to create a culture of quality.

In this context, $5 \mathrm{~S}$ is clearly an effective tool for a successful formative process. Its introduction reduces laboratory risks to the lowest level possible, thereby also reducing working hours and costs (it should not be forgotten that most students have no prior experience in technical laboratories), as well as extending the space available for the location of resources. It should be noted that unlike industrial 
laboratories, where productivity tends to prevail, teaching laboratories are devoted to the training of new professionals in different scientific and engineering fields.

Taking the above into account and by building upon the knowledge and experience acquired during the development of the first action, the next challenge was the implementation of $5 \mathrm{~S}$ in three different teaching laboratories (Chemical Engineering, Basic Chemistry, and Environmental Technology labs) to achieve and maintain order and maximize efficiency. This second action was carried out during the 2018/2019 academic year. In this case, the same procedure as for the warehouse was applied. To begin with, the work-team took the decision to consider the three laboratories as a single space instead of working with each of them individually. Taking into account that there was no inventory of the available material in each area, and knowing in advance that the same material was dispersed in different places, it was decided to implement the first $S$ (sort) simultaneously in all three laboratories. By contrast, the remaining steps were applied separately in each laboratory, although it was clear that decisions adopted in each laboratory had repercussions for the others.

The Seiri stage (1S) involved the complete emptying of all cabinets, drawers, and storage areas. An inventory of the contents was then carried out, classifying them according to the following criteria: Size, material (glass/plastic), quantity, and conservation status (used/new). Any unnecessary objects and waste collected were disposed of. Figure 7 shows images of this first step.

(a)

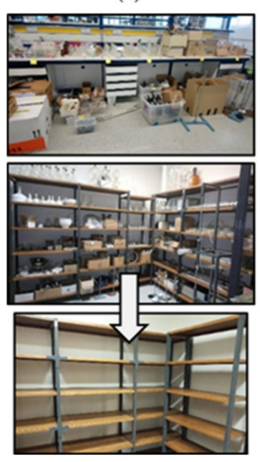

(b)

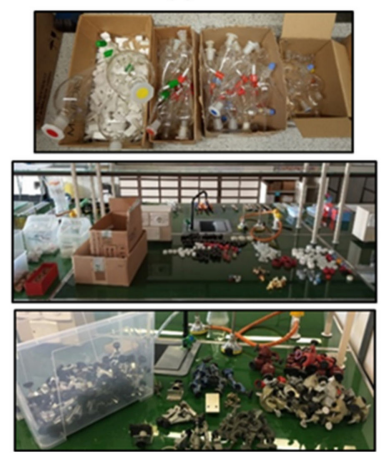

(c)

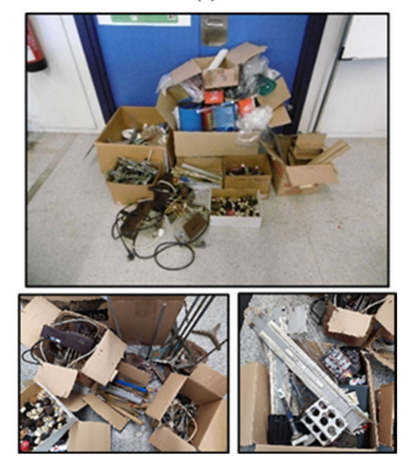

Figure 7. (a) Storage area emptying, (b) classification of different items, and (c) unnecessary material accumulated over the years.

Based on the aforementioned inventory, all material was organized and a first attempt was made to assign the most suitable place for their location (Seiton, 2S).

Thus, families of elements such as disposable material (e.g., filters, pipette tips, vials, or buckets), cleaning material, material related to various short-term activities carried out over the year, such as Science Week, first-year students' welcome program or University Orientation Workshop, personal protective equipment (e.g., goggles, gloves, laboratory coats or oven gloves) or equipment manuals, were established and a location for each one was designated.

In addition, a general rule was established whereby all units of the same type of material should remain in the same laboratory. For example, all Büchner/vacuum flasks were stored in the Basic Chemistry Laboratory, since they are mainly used during the practicals carried out therein. Consequently, sporadic users should go to this laboratory to collect the material and return it there after use. Although all decisions should be made with the aim of promoting an efficient workflow, this stage was the most complex to execute since large volumes of many different elements (more than 450 catalogued tools) were found during the first stage, thereby making the choice of the correct location for each item somewhat complicated at the first attempt.

The third step was Seiso (3S, Cleaning). First, a thorough general clean-up of all the equipment, supplies, and work areas was carried out. Here too, new working rules and habits were compulsory. For example, the working-team responsible for the project had to make it abundantly clear that the work area should be returned to the conditions it was in at the start of day, including putting away 
all tools, materials, and supplies used that day. There should be no doubt that it was much safer, comfortable, and productive to work in a neat and tidy work environment.

Figure 8 shows an example for Seiketsu, standardization stage (4S) where all risk, safety phrases, and hazard pictograms were updated following the Globally Harmonized System (GHS) [17].
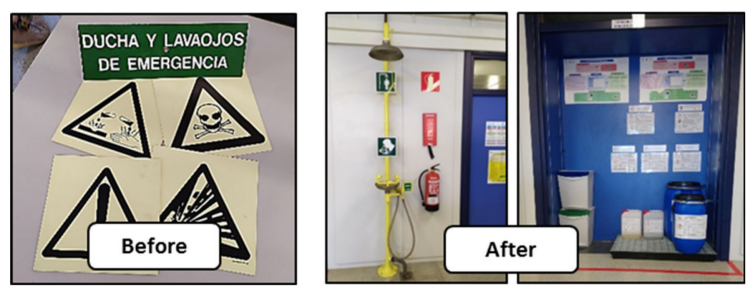

Figure 8. Comparison between before and after for Seiketsu, standardization stage (4S).

The last stage of the 5S strategy was Shitsuke, which is focused on maintaining standards and continuous improvement. In our case, sustainment or the maintaining of standards is probably the most difficult task of the $5 \mathrm{~S}$ management method taking into account the high number and range of users (each with their own specific needs) working in the laboratories during the year. With the aim of maintaining and improving the lean methodology implemented, new assessment criteria and a timetable for a periodic review of the $5 S$ status were set.

Just like an audit process, having everything inventoried, clean and tidy allowed the lab users to be fully aware of the real available potential in chemical reagents and lab supplies. In addition, by means of the database created by using the Quartzy online lab management platform, access to this information was achieved quickly and intuitively by any interested person without prior instruction.

The implementation of the management system was supervised and positively validated by an external certificate authority from the Quality and Innovation Unit of the UPV/EHU. To ensure the follow-up and the continuous improvement of the $5 \mathrm{~S}$ system in order to prevent/correct non-compliances concerning the standard requirements, both the chemical reagents warehouse and the three teaching laboratories will be reviewed on a yearly basis.

\subsection{Doing More and Better with Less}

Taking this pilot project conducted in the Faculty of Engineering Vitoria-Gasteiz as a starting point, the future goal should be to broaden this practice to the rest of the UPV/EHU centers. To this end, a joint public database would be at the disposal of members of the University listing all the available resources; incomprehensibly, despite belonging to the same university community, the use of each center's material is currently limited to the staff of each site. In other words, the implementation of this policy of sustainable development would enable the sharing and reuse of chemicals and lab supplies.

Turning this utopia into reality would result in clear economic benefits, but the most important advance would be the change in the mindset of all the actors involved, since the factors of sustainability and solidarity would become part of the decision-making equation $[18,19]$.

Besides, we need to remain ambitious with regard to the overall project: It should not be exclusively restricted to sharing or exchanging reagents and equipment but should be taken a step further towards the joint purchase of reagents in order to achieve sustainable consumption and production [20].

Obviously, implementation of a joint purchasing strategy is not as easy task. It requires a greater degree of forecast, commitment, and coordination skills from the members of the UPV/EHU, who up to now have been only required to ensure the practical work is carried out according to the teaching guides of each subject.

Humankind in general, and the University in particular, is usually driven by the adage "better the devil you know", being a society reluctant to make any large-scale changes that require it to operate outside of a "comfort zone" firmly established over the years. As shown in Figure 9, 19\% of University 
members related to Chemistry teaching labs would not take part in a joint purchase program regardless of the operating conditions or expected benefits.

The question posed in Figure 9 was part of a questionnaire that analyzed the degree of satisfaction of Teaching and Research Staff and Administration and Services Staff with the current system for the acquisition of chemical reagents and laboratory material, as well as their willingness to join in the aforementioned new purchasing strategy.

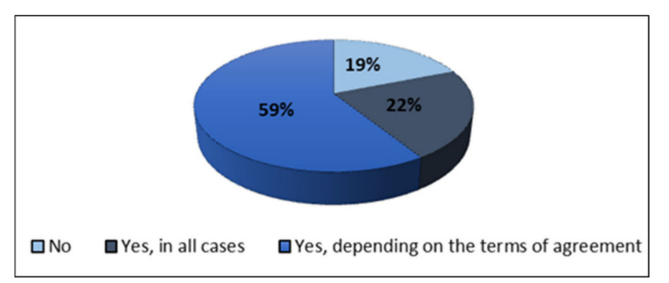

Figure 9. Answer to the question: Would you accept the centralization of purchase and storage of common chemical reagents?

Breaking down the results of the survey, $44 \%$ of respondents did not believe that the current chemical reagents management method applied in their respective Departments was the most appropriate.

In fact, $81 \%$ recognized that substances were simply stored, even in those cases where they were not expected to be used in the short to medium term (Figure 10). This policy results in the latter compounds becoming a hazardous waste entailing an additional expense for the treatment carried out by an external waste manager.

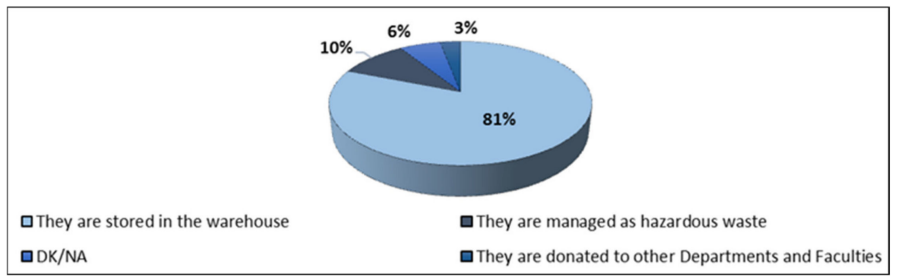

Figure 10. Answer to the question: What is done with chemical reagents when they are not expected to be used for a prolonged period of time?

Moreover, the willingness of respondents to contribute to a transformative change towards economic, environmental, and social sustainability was limited, since $75 \%$ of those who would accept the centralization of the lab-purchases would only get involved if there were economic and space advantages to be gained without having to take on more work than that established with the current management model.

In this regard, the fact that only $19 \%$ out of 167 people responded to the survey reinforced the cliché that University workers (Teaching and Research Staff and Administration and Services Staff) are guilty of laziness, a lack of involvement, an inability to innovate and adapt to the environment, and a low degree of environmental awareness [21].

Beyond the necessary time and the personal effort associated with such an innovation, what is really important for the joint purchasing strategy to be viable is the need to respond to a series of questions, such as "What chemical reagents do we have to buy?", "Who makes the orders?", "Where are the shared reagents stored?", "What is the payment method?", or "How are the chemicals transported from one center to another?".

It should be emphasized that in order for all partners to address these concerns, it is appropriate to proceed on the same premise: Standardize and keep the chemical reagents database updated. As has already been mentioned, the computerization of these data enables a search and detection of the common reagents employed in different centers, which would be the subject of the joint purchasing protocol. 
Described below are the steps that have to be followed to design an academic platform for collaborative chemical reagent order requests and management in teaching labs.

TASK 1. Inventory of chemical reagents used in laboratory practicals. Information regarding the chemical reagents used in the laboratory practices of the selected subjects was gathered (e.g., name of the reagent, CAS number, quantity used in each experiment) and collected in an inventory.

TASK 2. Identification of common needs. The reagents used in all the Departments involved in the project (common reagents) were identified. From a total of 102, 28 were classified as so-called "common reagents", which meant that two or more Departments made use of them (Table 2).

Table 2. Common reagent list.

\begin{tabular}{cccc}
\hline Compound & CAS & Compound & CAS \\
\hline Acetic acid & $64-19-7$ & Methanol & $67-56-1$ \\
Activated charcoal & $7440-44-0$ & Mohr's salt & $10045-89-3$ \\
Ammonia & $7664-41-7$ & Nitric acid & $7697-37-2$ \\
Ammonium chloride & $12125-02-9$ & Oxalic acid dihydrate & $6153-56-6$ \\
Barium chloride dihydrate & $10326-27-9$ & Potassium chromate & $7789-00-6$ \\
Calcium carbonate & $471-34-1$ & Potassium hydroxide & $1310-58-3$ \\
Calcium chloride dihydrate & $10035-04-8$ & Potassium iodide & $7681-11-0$ \\
Copper(II) nitrate trihydrate & $10031-43-3$ & Potassium nitrate & $7757-79-1$ \\
Copper(II) sulfate pentahydrate & $7758-99-8$ & Potassium permanganate & $7722-64-7$ \\
Ethanol & $64-17-5$ & Silver nitrate & $7761-88-8$ \\
Hexane & $110-54-3$ & Sodium carbonate & $497-19-8$ \\
Hydrochloric acid & $7647-14-5$ & Sodium chloride & $7647-14-5$ \\
Hydrogen peroxide & $7722-84-1$ & Starch & $9005-84-9$ \\
Lead(II) nitrate & $10099-74-8$ & Sulfuric acid & $7664-93-9$ \\
\hline
\end{tabular}

TASK 3. Cost benefit analysis. A comprehensive cost-benefit analysis of the joint purchase and management of the chemical reagents was established. The purpose of the cost benefit analysis is to help customers make informed choices taking into account both economic and environmental point of views.

To achieve this goal, the total price of a common reagent purchased individually by each Department (calculated as the sum of what each Department should pay) was compared with the total cost of the shared reagent jointly purchased. Subsequently, the optimal order quantity for each Department was calculated based on the size of the container of that reagent, thus calculating the cost of the reagent. The same procedure was carried out for the joint purchasing management of the rest of the common reagents and the differences between the individual and joint purchasing management were analyzed.

A practical example for the cost benefit analysis of ammonium chloride $\left(\mathrm{NH}_{4} \mathrm{Cl}\right)$ is shown in Table 3. $\mathrm{NH}_{4} \mathrm{Cl}$ is a quick-acting nitrogen fertilizer obtained as a by-product in different chemical processes, particularly from the Solvay process for the production of sodium carbonate. It cannot be stored together with strong acids and strong bases. In addition, it reacts violently with ammonium nitrate and potassium chlorate, causing fire and explosion hazards. Due to its hygroscopic nature and its tendency to cake, the expiry date should not exceed three years. The suggested disposal method involves the addition of sodium hydroxide to liberate ammonia and form the soluble sodium salt [22].

In this case, $\mathrm{NH}_{4} \mathrm{Cl}$ is employed in three Departments with a total consumption of $395 \mathrm{~g}$. Currently, each Department purchases a tin of $1000 \mathrm{~g}$ (minimum order quantity), which entails a consumption of $10 \%-15 \%$ each course. The overall purchase involves an expenditure of $30 €$ for the UPV/EHU. A joint purchasing effort would imply a single purchase of $10 €$. Moreover, the reagent sample would be entirely consumed throughout the third course without becoming a hazardous waste, as it expires after three years. By contrast, $60 \%-65 \%$ of the reagent (1800 g-1950 g) would be managed as laboratory reagent waste $(1850 € / T)$ in the case of individual purchasing. Summarizing, a joint purchasing strategy 
would lead to savings of $24 €$ in the case of $\mathrm{NH}_{4} \mathrm{Cl}$. On an overall basis, a joint purchase of "common reagents" would lead to economic savings of $542 €(31 \%)$.

Table 3. Cost benefit analysis of $\mathrm{NH}_{4} \mathrm{Cl}$ reagent purchase.

\begin{tabular}{|c|c|c|c|c|c|}
\hline \multirow[b]{2}{*}{ Department } & \multicolumn{3}{|c|}{ Reagent } & \multicolumn{2}{|c|}{ Hazardous Waste } \\
\hline & Quantity Used (g) & Minimum Order Quantity (g) & Cost $(€)$ & Quantity Produced (g) & $\operatorname{Cost}^{a}(€)$ \\
\hline Inorganic Chemistry & 160 & 1000 & 10 & 520 & 0.96 \\
\hline Analytical Chemistry & 134 & 1000 & 10 & 598 & 1.11 \\
\hline
\end{tabular}

Note: ${ }^{a}$ Classified and treated as laboratory reagent waste. ${ }^{b}$ The reagent is entirely consumed before the expiration date and no waste is generated.

TASK 4. Joint purchase protocol. A joint purchase procedure that enabled a more responsible and sustainable use of the chemical reagents. The aim is to propose a draft protocol to ensure the joint purchase, storage, and use of the chemical compounds employed in two or more departments. The following steps were established:

1. Creation of a joint committee formed by the coordinators of each department (or the person to whom it is delegated) and the Administration and Services Staff of each department responsible for the management of reagents. This committee will be in charge of:

- Defining the operating rules, including: The selection of people who will assume the roles of Coordinator and Secretary of the Committee (responsible for writing up the minutes as evidence of the economic management of the committee). The term of office of the Coordinator and the Secretary.

- Providing user access to all committee members to the Quartzy platform of each of the departments involved.

- Establishing the distribution methods and storage of the purchased items.

The department assuming the coordination of the Committee (rotating seat) will be responsible for the purchasing and distribution of the reagents among the rest of the departments.

The distribution will be made in an equitable way according to the indicated needs and the economic contribution made. In this case, the reagents will be distributed and stored in reused containers, which will be suitably labelled with the characteristics of the product purchased. Once the product is exhausted, the containers will be stored for later purchase.

Secondly, the following protocol has been proposed for the joint purchase of laboratory reagents:

2. Creation of a joint account with the involvement of the interested departments.

- The department to which the Committee coordinator belongs will be responsible for the financial management and will request a payment from the remaining departments corresponding to the cost of the reagents. Payment will be made via the TRAINERA accounting application of the UPV/EHU.

3. Determination of reagents needed for the current course and the first semester of the next course.

Definition of the characteristics of the purchase of reagents and the percentage established for each department. 


\subsection{Hidden Benefits}

Table 4 summarizes the pros and cons of a joint purchasing strategy. Despite the absence of significant savings, important environmental benefits would be expected from such an innovative management strategy:

- Better control and management of the chemical reagents used in the laboratories.

- Waste prevention due to lower generation of chemical residues.

- Reduction in the costs associated with the purchasing of reagents and the collection and handling of chemical waste.

Table 4. Advantages and difficulties of joint purchasing and management of chemical reagents within the UPV/EHU.

\begin{tabular}{ll}
\hline \multicolumn{1}{c}{ Advantages } & \multicolumn{1}{c}{ Difficulties } \\
\hline Better space management & Modification of the current reagent purchasing process \\
\hline Economic savings in purchases & Need for the systematization of inventories \\
\hline Reduction of reagents stock & Selection of a central stock room facility \\
\hline Promotion of synergies between Departments. & Reluctance to change \\
\hline Reduction of expired products & Economic needs to implement the new procedure \\
\hline Reduction in the cost of waste management & Establishment of new operating procedures \\
\hline
\end{tabular}

Indeed, the main difficulty that had to be overcome was the current chemicals purchasing policy within the UPV/EHU, which stipulated that ordering was carried out at departmental level using the departmental budget. In addition, the lack of a central stockroom facility hampered the management of common chemical reagents, and a laboratory-to-laboratory exchange strategy was set up as the most viable alternative.

\section{Conclusions}

The development of End-of-Degree Projects (EDPs) or End-of-Master Projects (EMPs) with specific sustainability aims and outcomes represents a way to promote the greening of campuses and mitigation of local environmental degradation, but even more importantly, it is also a way of educating all members of the university and persuading them to change their habits and customs to make them more sustainable and healthier.

The project presented herein, which includes the main actions developed in three different EDPs in the framework of the initiative "Campus Bizia Lab", seeks to encourage the implementation of good practices to reduce the amount and the dangerousness of hazardous waste generated by teaching, and to enable the waste to be managed properly. On a separate but related issue, safe facilities and appropriate operating methods that safeguard the health and well-being of the people inside the University are essential to achieve a level of excellence. The implementation of the $5 \mathrm{~S}$ strategy in the Universities (first and second actions of the project) is a way to build a culture of quality and continuous improvement, in addition to reinforcing responsible attitudes and good habits at work.

Carrying out this project has allowed us to know in detail the quantity of reagents that were stored, as well as to assess their status and discard those that were not in optimal conditions. The final result has been the implementation of an efficient chemical computerized reagent storage system that will enable a better use of the resources available the Chemical and Environmental Engineering Department.

The accomplishment of this project also enhanced the performance within the three teaching laboratories and had a positive effect on students, since a friendlier working environment encouraged them to undertake their laboratory practicals in an orderly and efficient manner, therefore improving their academic results. Thus, $5 \mathrm{~S}$ is an effective tool for a successful formative process. Its introduction 
ensures the reduction of laboratory risks to the lowest level possible, thereby also reducing working hours and costs (it should not be forgotten that most students have no prior experience in technical laboratories), as well as expanding the space available for the location of the resources. It is worth stating that $5 \mathrm{~S}$ methodology implementation success begins when all the involved members of an organization understand that $5 S$ is a new way of working towards an approach requiring the application of continuous effort.

In summary, this project entails the imperative commitment and involvement of the different partners (students, teaching staff, researchers, and administration and services personnel) to sustain over time the accomplishments affecting all the working-areas and to manage all the resources in a sustainable basis, which is yearly evaluated by an external agent, in this case the Quality and Innovation Unit of the UPV/EHU.

Furthermore, a draft protocol for the joint purchasing and management of the reagents was designed. The protocol could be extended to other departments, faculties, and services of the UPV/EHU, which would lead to a positive economic and environmental impact. This strategy would boost the circular economy and contribute to new sustainability challenges within the University itself.

Author Contributions: Conceptualization, methodology, project administration, writing-original draft, G.G. and J.G.; formal analysis, visualization, N.R. and Z.G.-d.-B.; writing-review and editing, A.S., A.T., D.E., and N.R.; funding acquisition, G.G. and A.T. All authors have read and agreed to the published version of the manuscript.

Funding: This research was funded by the University of the Basque Country (UPV/EHU) in the frame of Campus Bizia Lab Programme (CBL-17GALL and CBL-18GALL).

Acknowledgments: The technical and human backing provided by Marifeli Laresgoiti is gratefully acknowledged. Moreover, we are grateful to the Waste Management and Environmental Quality and Quality and Innovation Units of UPV/EHU.

Conflicts of Interest: There are no conflict to declare.

\section{References}

1. Salguero-Puerta, L.; Leyva-Díaz, J.C.; Cortés-García, F.J.; Molina-Moreno, V. Sustainability Indicators Concerning Waste Management for Implementation of the Circular Economy Model on the University of Lome (Togo) Campus. Int. J. Environ. Res. Public Health 2019, 16, 2234. [CrossRef] [PubMed]

2. Scopus Database. 2020. Available online: https://www.scopus.com/term/analyzer.uri?sid=92dd9a2ea7bf1ff1 $377 \mathrm{fdff90e76f5bf \& origin=resultslist \& src=s \& s=TITLE-ABS-KEY \% 28Circular+economy \% 29 \& sort=plf-f \& s}$ $\mathrm{dt}=\mathrm{b} \&$ sot $=\mathrm{b} \& \mathrm{sl}=31 \&$ count $=4977 \&$ analyzeResults $=$ Analyze + results \&txGid=e21b000b6cb95dd856f34ca87 4debc79 (accessed on 22 September 2020).

3. Kirchherr, J.; Reike, D.; Hekkert, M. Conceptualizing the circular economy: An analysis of 114 definitions. Resour. Conserv. Recycl. 2017, 127, 221-232. [CrossRef]

4. Kalmykova, Y.; Sadagopan, M.; Rosado, L. Circular economy-From review of theories and practices to development of implementation tools. Resour. Conserv. Recycl. 2018, 135, 190-201. [CrossRef]

5. Ellen MacArthur Foundation. Higher Education. 2017. Available online: https://www.ellenmacarthurfoun dation.org/our-work/activities/universities (accessed on 22 September 2020).

6. Campus Bizia Lab. 2019. Available online: https://www.ehu.eus/en/web/iraunkortasuna/campus-bizia-lab (accessed on 22 September 2020).

7. Hayles, C.S. INSPIRE sustainability internships. Int. J. Sustain. High. Educ. 2019, 20, 452-469. [CrossRef]

8. Faculty of Engineering of Vitoria-Gasteiz. Strategic Plan 2015/18. 2015. Available online: https://www.ehu.eus/documents/3049902/4867854/Plan+Estrat\%C3\%A9gico+2015+2018.pdf/c4345c b0-9617-4d1d-b4bb-ef2a808d7152 (accessed on 22 September 2020).

9. Randhawa, J.S.; Ahuja, I.S. 5S-A quality improvement tool for sustainable performance: Literature review and directions. Int. J. Qual. Reliab. Manag. 2017, 34, 334-361. [CrossRef]

10. Dolgin, E. How going green can raise cash for your lab. Nat. Cell Biol. 2018, 554, 265-267. [CrossRef] [PubMed]

11. Chitre, A.R. Implementing 5S Methodology for Lab Management in the Quality Assurance Lab of a Flexible Packaging Converter. Master's Thesis in Technology Management, University of Wisconsin-Stout, Menomonie, WI, USA, December 2010. 
12. Ramdass, K. Integrating $5 S$ principles with process improvement: A case study. In Proceedings of the 2015 Portland International Conference on Management of Engineering and Technology (PICMET), Portland, OR, USA, 2-6 August 2015; Institute of Electrical and Electronics Engineers (IEEE): New York, NY, USA, 2015; pp. 1908-1917.

13. Kanamori, S.; Shibanuma, A.; Jimba, M. Applicability of the $5 S$ management method for quality improvement in health-care facilities: A review. Trop. Med. Health 2016, 44, 1-8. [CrossRef] [PubMed]

14. EUSKALIT. Manual EUSKALIT de la Metodología 5S; EUSKALIT- Fundación Vasca para la Calidad: Zamudio, Spain, 2006; ISBN 84-932105-9-5.

15. Sustainability Directorate and Educational Advisory Service. Hazardous Waste Treatment Cost. 2019. Available online: https://www.ehu.eus/documents/4736101/5153347/CLASIFICACI\%C3\%93N+RP.pdf?versio $\mathrm{n}=1.0$ (accessed on 22 September 2020).

16. Sustainability Directorate and Educational Advisory Service. Hazardous Waste Classification. 2019. Available online: https://www.ehu.eus/documents/4736101/5153347/Incompatibilidades+almacenamiento+residuos .pdf?version=1.0 (accessed on 22 September 2020).

17. United Nations. Globally Harmonized System of Classification and Labelling of Chemicals (GHS). In Globally Harmonized System of Classification and Labelling of Chemicals (GHS); United Nations Economic Commission for Europe: Geneva, Switzerland, 2011; ISBN 978-92-1-117042-9.

18. Montañés, M.T.; Palomares, A.E.; Sánchez-Tovar, R. Integrating sustainable development in chemical engineering education: The application of an environmental management system. Chem. Educ. Res. Pract. 2012, 13, 128-134. [CrossRef]

19. Cheng, W.; Appolloni, A.; D'Amato, A.; Zhu, Q. Green public procurement, missing concepts and future trends-A critical review. J. Clean. Prod. 2018, 176, 770-784. [CrossRef]

20. Sustainable Development Goals. Goal 12: Ensure Sustainable Consumption and Production Patterns. 2019. Available online: https://www.un.org/sustainabledevelopment/sustainable-consumption-production/ (accessed on 22 September 2020).

21. The Guardian. Spain Shown perils of Climate Change. 2017. Available online: https://www.theguardian.co m/environment/2007/nov/10/flooding.climatechange (accessed on 22 September 2020).

22. Pohanish, R.P. Sittig's Handbook of Toxic and Hazardous Chemicals and Carcinogens. In Sittig's Handbook of Toxic and Hazardous Chemicals and Carcinogens; William Andrew: Norwich, NY, USA, 2012; p. 165.

Publisher's Note: MDPI stays neutral with regard to jurisdictional claims in published maps and institutional affiliations.

(C) 2020 by the authors. Licensee MDPI, Basel, Switzerland. This article is an open access article distributed under the terms and conditions of the Creative Commons Attribution (CC BY) license (http://creativecommons.org/licenses/by/4.0/). 